\title{
Safety of bivalirudin versus unfractionated heparin in endovascular revascularization of peripheral arteries in short- and long-term follow-up
}

\author{
Joanna Wojtasik-Bakalarz, Paweł Kleczyński, Wojciech Zasada, Tomasz Rakowski, Salech Arif, \\ Krzysztof Bartuś, Dariusz Dudek, Stanisław Bartuś \\ $2^{\text {nd }}$ Department of Cardiology, Jagiellonian University Medical College, Krakow, Poland
}

Adv Interv Cardiol 2019; 15, 1 (55): 91-97

DOI: https://doi.org/10.5114/aic.2019.81757

\begin{abstract}
A bstract
Introduction: Patients with peripheral artery disease (PAD) are considered as a high-risk group for hemorrhagic events.

Aim: To assess the safety of bivalirudin vs. unfractionated heparin (UFH) in percutaneous peripheral interventions (PPI) in shortand long-term follow-up.

Material and methods: The retrospective single-center, observational study included 160 patients, undergoing PPI. Patients were divided into 2 groups based on the use of anticoagulation - unfractionated heparin (UFH group) or bivalirudin (Biv. group) and observed up to 5 years.

Results: The UFH group consisted of 101 patients and the Biv. group consisted of 59. We registered the following end points during in-hospital observation: 1 death (0.63\% Biv, $p=0.18), 12$ hematomas at puncture site $(0.63 \%$ Biv. vs. $7.05 \%$ UFH, $p=0.04)$, 2 pseudoaneurysms (1.27\% UFH, $p=0.29$ ), thrombosis ( $0.63 \% \mathrm{UFH}, p=0.45), 1$ bleeding from puncture site $(0.63 \% \mathrm{UFH}, p=0.45)$. The total number of hemorrhagic complications was $1.24 \%$ in the Biv. group and $8.07 \%$ in the UFH group $(p=0.04)$. During longterm follow-up of $65.7 \pm 36.4$ months the all-cause mortality rate was higher in the Biv. group (8.59\% Biv vs. $0 \%$ in UFH group, $p=0.009)$. Regression analysis showed that bivalirudin administration is a risk factor for increased mortality risk $(p=0.003$, $\mathrm{OR}=15,95 \% \mathrm{Cl}: 3.3-107.8)$.

Conclusions: Usage of UFH was associated with a higher number of hemorrhagic complications, especially hematomas at the puncture site in comparison to patients receiving bivalirudin.
\end{abstract}

Key words: bivalirudin, heparin, peripheral artery disease, long-term mortality.

S u m m a ry

In patients undergoing peripheral vascular interventions bivalirudin can be a valid option for anticoagulation during procedure. Impact of bivalirudin on decreased number of bleeding complications and low risk of thromboembolic events, can translate to increased safety of percutaneous peripheral interventions and can reduce cost of hospitalization and ambulatory care of patients with peripheral artery disease.

\section{Introduction}

Bivalirudin is an anticoagulant drug, a reversible direct thrombin inhibitor, used mostly in percutaneous coronary interventions ( $\mathrm{PCI}$ ) [1]. The pharmacological profile with a short half-life (around $25 \mathrm{~min}$ ) makes bivalirudin an option for patients with a contradiction for unfractionated heparin (UFH) or high risk of bleeding [1, 2]. Patients with peripheral artery disease (PAD) can usually be considered as a high-risk group for hemorrhagic events [3]. According to ESC guidelines bivalirudin can be used as the primary anticoagulation in patients with a history of heparin-induced thrombocytopenia [4-6]. Due to the reported lower bleeding complication rate compared to UFH in patients with high risk of hemorrhagic it is worth considering bivalirudin administration [4]. Also, in patients with non-ST-elevation myocardial infarction

Corresponding author:

Stanisław Bartuś MD, PhD, 2 ${ }^{\text {nd }}$ Department of Cardiology, Jagiellonian University Medical College, 17 Mikołaja Kopernika St, 31-501 Krakow, Poland, phone: +48 12424 7181, e-mail: stanislaw.bartus@uj.edu.pl

Received: 27.05.2018, accepted: 4.11.2018. 
(NSTEMI) bivalirudin is an alternative to UFH administered combined with GP IIb/IIla during PCI [5]. Nowadays, indications for bivalirudin are well defined in guidelines for coronary interventions, but there is still a lack of randomized trials focused on anticoagulation during peripheral procedures [6].

\section{Aim}

Thus, we aimed to investigate the safety of bivalirudin vs. UFH in percutaneous peripheral interventions (PPI) in short- and long-term follow-up, especially risk of bleeding and thromboembolic complications and major cardiovascular and peripheral events.

\section{Material and methods}

In our retrospective single-center, observational study all data were gathered between 2006 and 2014. One hundred sixty-one patients who underwent PPI were included. The study included patients who underwent different types of PPI: in carotid arteries, in arteries above the knee, in arteries below the knee, in subclavian arteries. We excluded patients after PPI of renal arteries, arteriovenous fistula, in-stent restenosis or with chronic total occlusion. Patients with acute limb ischemia or qualified for surgery of peripheral artery disease were excluded from the study (Figure 1).

Patients were divided into two groups according to the anticoagulant used during PPI: unfractionated heparin (UFH group) or bivalirudin (Biv. group). Baseline clinical data were assessed. Before the index procedure routine laboratory tests were performed. Procedures were performed in compliance with a standardized institutional protocol. Dosage of UFH was adjusted to patients' weight. Bivalirudin was administered as a bolus before the PPI and continued as intravenous infusion during the procedure $(0.75 \mathrm{mg} / \mathrm{kg}$ bolus and $1.75 \mathrm{mg} / \mathrm{kg} / \mathrm{h}$ infusion) under activated clotting time control. Procedures were performed with the antegrade technique. Vascular sheets were removed $4 \mathrm{~h}$ after the procedure and hemostasis was achieved by manual compression. After the procedure and during in-hospital observation patients were assessed for major cardiovascular events (MACCE) such as all-cause mortality, myocardial infarction, stroke/ transient ischemic attack, urgent $\mathrm{PCl}$ or coronary artery bypass grafting; bleeding complications (classified according to BARC criteria), and for major peripheral events (MAPE) such as vascular complications (bleeding from access site, thrombosis, hematoma, vessel perforation, arteriovenous fistula, pseudoaneurysm) and amputations. In long-term follow-up patients were observed for MACCE, rePPIs, amputations and deaths. The follow-up of the patients was conducted up to 5 years. Data from the Polish National Health Fund were used.

All procedures performed in this study were in accordance with the ethical standards and complied with the Declaration of Helsinki for medical research.

\section{Statistical analysis}

Results were presented as number of patients (percentage), mean value with standard deviation (SD) or median with interquartile range (IQR), as appropriate. For dichotomous variables the $\chi^{2}$ test and Fisher's test were used. In the case of dichotomous variables, the Mann-Whitney U-test was used. The Kaplan-Meier method was used to assess the difference in mortality during follow-up between patients. Additionally, multivariable

\footnotetext{
- with acute limb ischemia

- qualified for surgery treatment of peripheral artery disease

- with severe kidney failure
}

Patients excluded from the study:

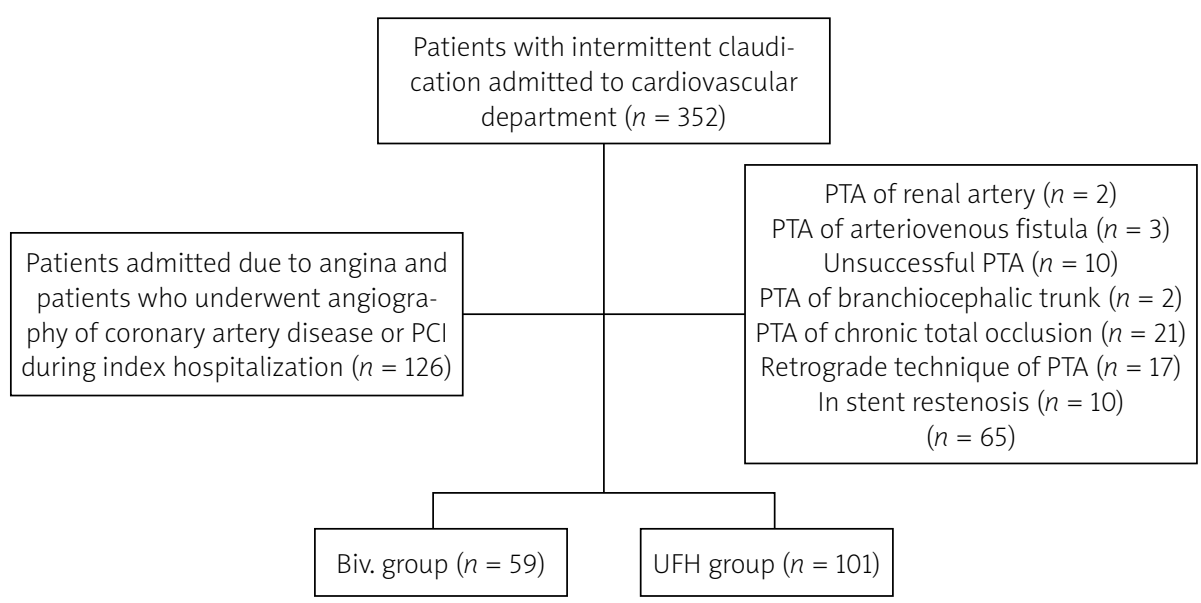

Figure 1. Plot: patient inclusion algorithm

Biv. - bivalirudin, $\mathrm{PCl}$ - percutaneous coronary intervention, PTA - percutaneous transluminal angioplasty, UFH - unfractionated heparin. 
regression analysis (Cox's regression) was performed to find predictors of long-term mortality. All tests were twotailed, and a $p$-value of $<0.05$ was considered statistically significant.

\section{Results}

We included 161 patients with established indications for PPI. The UFH group consisted of 102 patients ( $80 \%$ men), and the bivalirudin group (Biv. group) consisted of 59 patients (76.2\% men). Demographic data are shown in Table I. Mean age of patients was $65.4 \pm 7.2$ years in the Biv. group and $65.1 \pm 8.5$ years in the UFH group. Rates of cardiovascular risk factors were similar between the groups except oral treatment of diabetes (in the UFH group it was higher, $p=0.01$ ). Nineteen (32\% in Biv. group) vs. 18 (17.8\% in UFH group) percutaneous interventions in carotid arteries were performed; 37 (62.7\% Biv. group) vs. 75 (72\% in UFH group) in arteries above the knee, 2 (3.4\% Biv. group) vs. 7 (6.9\% UFH group) in arteries below the knee, and 1 in subclavian artery intervention (both groups). The most common access site was the femoral artery: 31 (52.5\%) in the Biv and 79 (49\%) in the UFH group.

\section{In-hospital observation}

Mean in-hospital stay was $7.3 \pm 4.8$ (Biv) vs. $5.9 \pm 3.8$ (UFH) days $(p=0.06)$. One death in the Biv. group was registered $(0.63 \%$ Biv, $p=0.18)$. We observed 12 hematomas at the puncture site $(0.63 \%$ Biv vs. $7.05 \%$ UFH, $p=0.04), 2$ pseudoaneurysms (1.27\% UFH, $p=0.29)$, 1 case of thrombosis $(0.63 \%$ UFH, $p=0.45)$, and 1 case of bleeding from the puncture site $(0.63 \%$ UFH, $p=0.45)$. Arteriovenous fistula, retroperitoneal bleeding and loss of limb were not observed during hospital observation. There were no statistically significant drops of hemoglobin levels in any group (Table II). The total number of hemorrhagic complications was $1.24 \%$ in the Biv. group and $8.07 \%$ in the UHF group ( $p=0.04$, Table III).

\section{Long-term follow-up}

Mean time of long-term follow-up was $65.7 \pm 36.4$ months. All-cause mortality was higher in the Biv. group (8.69\%, vs. $7 \%$ in UFH group, $p=0.009$; Figure 2 ). The repeated $\mathrm{PPI}$ rate was higher in the Biv. group (6.8\% vs. $11.8 \%$ in Biv. group). In the logistic regression model, with multiple independent variables bivalirudin administration was associated with higher risk of all-cause mortality than UFH (OR = 15. 95\% Cl: 3.3-107.8; Table III, Figure 2).

\section{Discussion}

Bivalirudin is a well-known anticoagulant, used during percutaneous procedures, especially coronary interven-

Table I. Demographic and clinical characteristics

\begin{tabular}{|c|c|c|c|}
\hline Variable & Biv. group $\%(n=59)$ & UFH group $\%(n=102)$ & $P$-value \\
\hline Age [years] & 65.42 & 65.14 & 0.95 \\
\hline Sex (male) & $76.2 \%(45)$ & $80 \%(81)$ & 0.53 \\
\hline Coronary artery disease & $88 \%(52)$ & $92 \%(93)$ & 0.99 \\
\hline $\mathrm{PCl}$ in past & $40.6 \%(24)$ & $48.5 \%(49)$ & 0.47 \\
\hline CABG in past & $11.8 \%(7)$ & $8.9 \%(9)$ & 0.46 \\
\hline History of PPI & $25 \%(15)$ & $40.1 \%(41)$ & 0.10 \\
\hline History of CAS & $1.7 \%(1)$ & $5.9 \%(6)$ & 0.23 \\
\hline DM: & $30.5 \%(18)$ & $34.6 \%(35)$ & \\
\hline Diet & $6.7 \%(4)$ & $1 \%(1)$ & 0.03 \\
\hline Oral treatment & $5.1 \%(3)$ & $19.8 \%(20)$ & 0.01 \\
\hline Insulin treatment & $18.6 \%(11)$ & $13.8 \%(14)$ & 0.35 \\
\hline Hypertension & $81 \%(48)$ & $83 \%(84)$ & 0.76 \\
\hline Hypercholesterolemia & $79.6 \%(47)$ & $86 \%(87)$ & 0.3 \\
\hline Smoking & $22 \%(13)$ & $22.7 \%(23)$ & 0.34 \\
\hline History of stroke & $23.7 \%(14)$ & $15.8 \%(16)$ & 0.003 \\
\hline History of TIA & $1.7 \%(1)$ & $1.9 \%(2)$ & 0.59 \\
\hline
\end{tabular}

$C A B G$ - coronary artery bypass grafting, CAS - carotid artery stenting, DM - diabetes mellitus, PCI-percutaneous coronary intervention, PPI - percutaneous peripheral intervention, TIA - transient ischemic attack. 
Table II. Laboratory tests before and after procedure

\begin{tabular}{|c|c|c|c|c|c|}
\hline \multirow[t]{2}{*}{ Parameter } & \multicolumn{2}{|c|}{ Biv. group \% $(n=59)$} & \multicolumn{2}{|c|}{ UFH group $\%(n=101)$} & \multirow[t]{2}{*}{$P$-value } \\
\hline & Before PPI & After PPI & Before PPI & After PPI & \\
\hline Hemoglobin level [g/dl] & $15.8 \pm 0.5$ & $12.23 \pm 2.37$ & $13.75 \pm 1.53$ & $12.06 \pm 2.05$ & 0.2 \\
\hline Platelets level [× 1000/ml] & $211.91 \pm 56.25$ & $209.7 \pm 85$ & $208.03 \pm 63.87$ & $193.3 \pm 61.87$ & 0.6 \\
\hline eGFR $\left[\mathrm{ml} / \mathrm{min} / 1.73 \mathrm{~m}^{2}\right]$ & $77.89 \pm 22.87$ & $47 \pm 26$ & $82.47 \pm 25.74$ & $56.88 \pm 6.9$ & 0.5 \\
\hline
\end{tabular}

eGFR - estimated glomerular filtration rate.

Table III. In hospital complications, long-term follow-up data and results of regression analysis

\begin{tabular}{|c|c|c|c|}
\hline Variable & Biv. group \% (n) & UFH group \% (n) & $P$-value \\
\hline \multicolumn{4}{|l|}{ In-hospital observation: } \\
\hline Death & $0.63 \%(1)$ & 0 & 0.18 \\
\hline Hematoma at puncture site & $0.63 \%(1)$ & $7 \%(11)$ & 0.04 \\
\hline Pseudoaneurysm & 0 & $1.27 \%(2)$ & 0.29 \\
\hline Thrombosis in target artery & 0 & $0.63 \%(1)$ & 0.45 \\
\hline Bleeding from puncture site & 0 & $0.63 \%(1)$ & 0.45 \\
\hline All complications & $1.24 \%(2)$ & $8.07 \%(15)$ & 0.04 \\
\hline \multicolumn{4}{|l|}{ Long-term follow-up: } \\
\hline $\mathrm{PCl}$ & $13.2 \%(17)$ & $37.5 \%(48)$ & 0.28 \\
\hline CABG & $1.56 \%(2)$ & $0.78 \%(1)$ & 0.17 \\
\hline Death (all-cause) & $8.59 \%(11)$ & $7 \%(8)$ & 0.009 \\
\hline Stroke & $0 \%$ & $1.56 \%(2)$ & 0.34 \\
\hline ACS & $1.56 \%(2)$ & $3.13 \%(4)$ & 0.87 \\
\hline GIB & 0 & 0 & \\
\hline Heart failure & $3.13 \%(4)$ & $6.25 \%(8)$ & 0.82 \\
\hline Kidney failure & 0 & 0 & \\
\hline Amputation & $1.56 \%(2)$ & $0.78 \%(1)$ & 0.16 \\
\hline CAS & $0.78 \%(1)$ & 0 & 0.12 \\
\hline rePPI & $11.8 \%(7)$ & $6.86 \%(7)$ & \\
\hline \multicolumn{4}{|c|}{ Regression analysis (Cox's regression) } \\
\hline Variable & OR & $95 \% \mathrm{Cl}$ & $P$-value \\
\hline Anticoagulation (bivalirudin) & 15.02 & $3.3-107.8$ & $0.0003^{*}$ \\
\hline ACS & 0.3 & $0.06-1.67$ & 0.2 \\
\hline $\mathrm{PCl}$ or $\mathrm{CABG}$ & 1.2 & $0.2-5.6$ & 0.79 \\
\hline Sex & 1.3 & $0.2-6.7$ & 0.7 \\
\hline Age & 0.9 & $1.04-1.06$ & 0.8 \\
\hline
\end{tabular}

ACS - acute coronary syndrome, CABG - coronary artery bypass grafting, CAS - carotid artery stenting, GIB - gastrointestinal bleeding, PCI - percutaneous coronary intervention, rePPI-repeated percutaneous peripheral intervention.

tions [1]. We confirmed a lower rate of periprocedural complications in bivalirudin with the rate of all in-hospital complications at $1.24 \%$, which makes our results favorable compared to already published data. Usage of bivalirudin was not associated with any ischemic events, such as stroke, acute coronary syndrome (ACS) or throm- 
bosis during in-hospital observation. We reported one case of early thrombosis in the UFH group. However, long-term follow-up showed a higher rate of deaths in the bivalirudin group $(8.69 \% \mathrm{Bi}, p=0.0095)$. These data were confirmed in our long-term follow-up. It is difficult to discuss that results, due to lack of randomized trials or large reports about safety of bivalirudin in peripheral interventions. Therefore, we can only extrapolate the results from published trials in patients who underwent coronary angioplasty.

In the REPLACE-2 trial (patients with stable CAD) the anticoagulant effect of bivalirudin combined with GP IIb/ IIla was comparable to UFH combined with GP Ila/IIla [7]. Based on the ISAR-REACT 3 trial, bivalirudin is associated with a lower rate of bleeding events in patients with stable CAD with no influence on mortality during observation [8]. Also, in the ACUITY study bivalirudin (in $7.4 \%$ cases with GP Ilb/IIla) versus UFH plus GP II/ IIla inhibitors was favorable in combined ischemic and hemorrhagic complications in 30 days' observation $(p=0.02)$. In hemorrhagic complications alone, this difference is more visible in 1-year observation (3.0\% vs. $5.7 \% ; p<0.001$ ) [9]. The ISAR-REACT 4 study (patients with NSTEMI) showed a low rate of serious bleeding events in the group of patients with bivalirudin $(2.6 \%$ vs. $4.6 \%$ of UFH) [10]. The results of the HORIZONS-AMI study showed that treatment with bivalirudin (vs. UFH plus GP Ila/IIla inhibitors) results in lower rates of cardiac mortality $(1.8 \%, p=0.03)$ and all-causes deaths $(2.1 \%, p=0.047)$ in 30 days' FU [11]. It also confirms reductions of major bleeding events in 1-year observation [11]. However, in the HORIZON-AMI study and EUROMAX study the problem of acute in-stent thrombosis was reported [11, 12]. Frequency of stent thrombosis was higher in the bivalirudin group than in the control group (1.6\% vs. $0.5 \% ; p=0.02)$, with a significant difference within the first $24 \mathrm{~h}$ and without a difference in subacute stent thrombosis at 30 days of follow-up [12]. Despite all these results, UFH iv is still a standard anticoagulant in $\mathrm{PCl}$. In the Bravo-3 trial in patients with PAD and severe aortic stenosis, at 30 days of follow-up, use of bivalirudin during transcatheter aortic valve implantation was not associated with reduction of cardiovascular events or bleeding events [13]. Bivalirudin use nevertheless was associated with higher prevalence of acute kidney failure ( $p=0.03$ ) [13]. Pseudoaneurysms are common complications after artery puncture during endovascular procedures. The frequency of femoral pseudoaneurysm varies between $0.5 \%$ after a diagnostic coronary procedure and $8 \%$ after endovascular coronary interventions. Risk of this vascular complication is greater in patients with atherosclerosis, hypertension, obesity, or kidney failure [14-16]. We observed a frequency of $1.27 \%$ for pseudoaneurysms after PPI in the group of patients treated with heparin and none in the bivalirudin group. Compared to

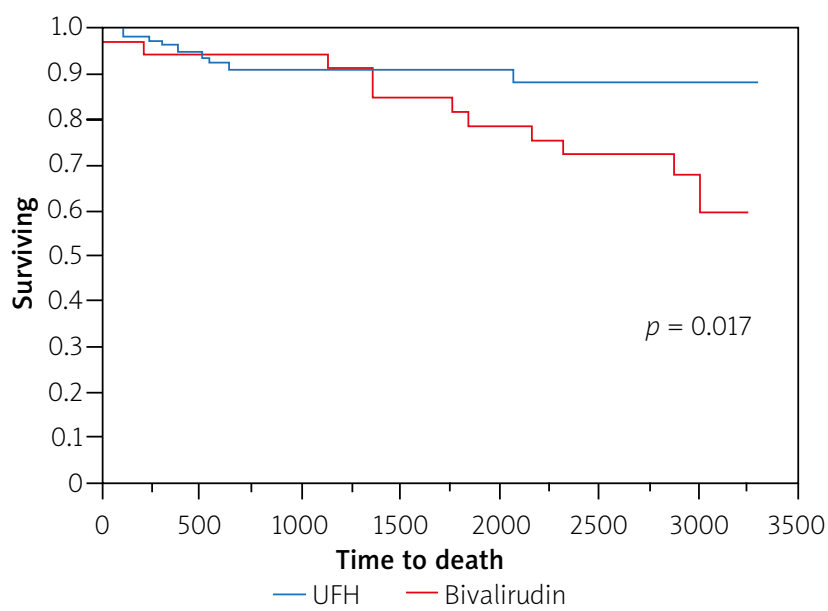

Figure 2. Kaplan-Meier curves for survival after percutaneous peripheral interventions stratified by the use of unfractionated heparin (UFH) or bivalirudin

results of patients after $\mathrm{PCl}$ treated with bivalirudin alone by Ormiston el al., hematoma occurred less frequently after PPI than after $\mathrm{PCl}-2 \%$ vs. $0.63 \%$ in our research [17].

Though patients with coronary artery disease have the same risk factors as patients with PAD and percutaneous procedures have some similarities, it is worth pointing out that peripheral procedures are usually longer than $\mathrm{PCl}$ and result in a higher rate of bleeding complications, and the risk in patients with PAD is higher than in patients without PAD $[3,18]$. That makes studies of PPI relevant and necessary.

The bleeding risk in patients undergoing PPI of lower limb arteries associated with anticoagulant used during the procedure is not well defined. Abtahian et al. presented comparable results of bleeding events in both groups during $\mathrm{PCl}$. There were no differences between bivalirudin and UFH in risk of major bleeding (1.8\% UFH vs. $2.4 \%$ bivalirudin, $p=0.305)$, or combined major and minor bleeding (4.3\% for both). In-hospital observation also shows similar results for rates of death, $\mathrm{MI}$ or re- $\mathrm{PCI}$ [19]. In published studies bivalirudin seems to be a safe option for patients who underwent PPI. Rates of major ischemic and adverse bleeding events are low: cerebrovascular events $(0.3 \%)$, acute renal failure $(0.3 \%)$, major bleeding (0.8\%), distal embolization (3.0\%), access site complications $(0.5 \%)$, minor amputation $(0.5 \%)$ or bleeding event requiring red blood cell transfusions $(0.9 \%, p=0.01)$ [20]. According to Oritz et al., patients who underwent percutaneous vascular interventions with bivalirudin usage have a lower rate of local bleeding complications (access site hematoma) ( $2.4 \%$ vs. $3.9 \%, p=0.018)$ and shorter time of hospitalization (1.0 vs. 1.2 days, $p<0.001$ ) [21]. There are no differences in access site occlusion, distal embolization or mortality. A study by Shammas et al. resulted in an overall complication rate of $4.2 \%$ with bivalirudin vs an event rate of $9.2 \%$ for UFH during PPI [22]. 
Sheikh et al. found no differences in procedural success or major and minor bleeding. In contrast to the results of Ortiz et al., Sheikh et al. and our study did not confirm reduction of length in hospital stay [23]. Moreover, the APPROVE trial defined predictors for bleeding events in patients treated with bivalirudin as the primary anticoagulant, such as female gender, exchange to larger sheet and low weight ( $<80 \mathrm{~kg}$ males, $<62 \mathrm{~kg}$ females). The study also showed a low rate of ischemic events, around $1.4 \%$, and a major hemorrhage rate at $2.2 \%$ [24]. In our study we did not confirm female gender as a risk factor for bleeding events.

Unfortunately, information about long-term outcomes of bivalirudin in patients undergoing peripheral vascular interventions are limited and trials focus only on 30-day follow-up. The safety profile of bivalirudin in the context of bleeding events is similar in published studies. The mechanisms through which bivalirudin increased mortality in long-term follow-up are unknown and our collected data are insufficient to confirm the exact pathomechanism leading to the suggested higher risk of death. This topic should be further explored in randomized, preferably multicenter trials and confirmed in large-sample size studies.

\section{Limitations of study}

Our study has obvious limitations. It was non-randomized, retrospective and single center, with a rather small patient population. However, due to the lack of data on usage of bivalirudin in patients undergoing peripheral interventions, our study represents real-world data.

\section{Conclusions}

In patients undergoing peripheral vascular interventions bivalirudin can be a valid option for anticoagulation during the procedure. The impact of bivalirudin on the decreased number of bleeding complications and low risk of thromboembolic events can translate to increased safety of PPIs and can reduce costs of hospitalization and ambulatory care of patients with peripheral artery disease.

\section{Conflict of interest}

The authors declare no conflict of interest.

\section{References}

1. Warkentin T, Greinacher A, Koster A. Bivalirudin. Thromb Haemost 2008; 99: 830-9.

2. Kastrati A, Neumann FJ, Mehilli J, et al. Bivalirudin versus unfractionated heparin during percutaneous coronary intervention. N Engl J Med 2008; 359: 688-96.

3. Baumann F, Husmann M, Benenati J, et al. Bleeding risk profile in patients with symptomatic peripheral artery disease. J Endovasc Ther 2016; 23: 468-71.

4. Ibanez B, James S, Agewall S, et al. 2017 ESC Guidelines for the management of acute myocardial infarction in patients present- ing with ST-segment elevation: The Task Force for the management of acute myocardial infarction in patients presenting with ST-segment elevation of the European Society of Cardiology (ESC). Eur Heart J 2018; 39: 119-77.

5. Roffi M, Patrono C, Collet JP, et al. 2015 ESC Guidelines for the management of acute coronary syndromes in patients presenting without persistent ST-segment elevation: Task Force for the Management of Acute Coronary Syndromes in Patients Presenting without Persistent ST-Segment Elevation of the European Society of Cardiology (ESC). Eur Heart J 2016; 37: 267-315.

6. Windecker S, Kolh P, Alfonso F, et al. 2014 ESC/EACTS Guidelines on myocardial revascularization. Eur Heart J 2014; 35: 2541-619.

7. Lincoff AM, Bittl J, Harrington R, et al. Bivalirudin and provisional glycoprotein Ilb/IIla blockade compared with heparin and planned glycoprotein Ilb/IIla blockade during percutaneous coronary intervention: REPLACE-2 randomized trial. JAMA 2003; 289: 853-63.

8. Schulz S, Mehilli J, Ndrepepa G, et al. Bivalirudin vs. unfractionated heparin during percutaneous coronary interventions in patients with stable and unstable angina pectoris: 1-year results of the ISAR-REACT 3 trial. Eur Heart J 2010; 31: 582-7.

9. Stone $\mathrm{G}$, White $\mathrm{H}$, Ohman E, et al. Bivalirudin in patients with acute coronary syndromes undergoing percutaneous coronary intervention: a subgroup analysis from the Acute Catheterization and Urgent Intervention Triage strategy (ACUITY) trial. Lancet 2007; 369: 907-19.

10. Schulz S, Kastrati A, Ferenc M, et al. One-year outcomes with abciximab and unfractionated heparin versus bivalirudin during percutaneous coronary interventions in patients with non-STsegment elevation myocardial infarction: updated results from the ISAR-REACT 4 trial. Eurolntervention 2013; 9: 430-6.

11. Mehran R, Brodie B, Cox D, et al. The Harmonizing Outcomes with RevasculariZatiON and Stents in Acute Myocardial Infarction (HORIZONS-AMI) Trial: study design and rationale. Am Heart J 2008; 156: 44-56.

12. Steg P, van't Hof A, Hamm C, et al. Bivalirudin started during emergency transport for primary PCI. N Engl J Med 2013; 369: 2207-17.

13. Dangas $G$, Lefèvre $T$, Kupatt $C$, et al. Bivalirudin versus heparin anticoagulation in transcatheter aortic valve replacement: the randomized BRAVO-3 trial. J Am Coll Cardiol 2015; 66: 2860-8.

14. Kleczynski P, Rakowski T, Dziewierz A, et al. Ultrasound guided thrombin injection in the treatment of iatrogenic arterial pseudoaneurysms: single-center experience. J Clin Ultrasound 2014; 42: 24-6.

15. Krueger K, Zaehringer M, Strohe D, et al. Postcatheterization pseudoaneurysm: results of US-guided percutaneous thrombin injection in 240 patients. Radiology 2005; 236: 1104-10.

16. Middleton WD, Dasyam A, Teefey SA. Diagnosis and treatment of iatrogenic femoral artery pseudoaneurysms. Ultrasound $\mathrm{Q}$ 2005; 21: 3-17.

17. Ormiston J, Shaw B, Panther M, et al. Percutaneous coronary intervention with bivalirudin anticoagulation, immediate sheath removal, and early ambulation: a feasibility study with implications for day-stay procedures. Catheter Cardiovasc Interv 2002; 55: 289-93.

18. Arif S, Bartus S, Rakowski T, et al. Comparison of radiation dose exposure in patients undergoing percutaneous coronary intervention vs. peripheral intervention. Adv Interv Cardiol 2014; 10: 308-13.

19. Abtahian F, Waldo S, Jang I. Comparison of heparin and bivalirudin in patients undergoing percutaneous coronary intervention 
without use of glycoprotein IIb/IIla inhibitors. Catheter Cardiovasc Interv 2015; 86: 390-6.

20. Wayangankar S, Abu-Fadel M, Aronow HD, et al. Hemorrhagic and ischemic outcomes after bivalirudin versus unfractionated heparin during carotid artery stenting: a propensity score analysis from the NCDR. Circ Cardiovasc Interv 2013; 6: 131-8.

21. Oritz D, Singh $M$, Jahangir $A$, et al. Bivalirudin versus unfractionated heparin during peripheral vascular interventions: a propensity-matched study. Catheter Cardiovasc Interv 2017; 89: 408-13.

22. Shammas N, Lemke J, Dippel E, et al. Bivalirudin in peripheral vascular interventions: a single center experience. I Invasive Cardiol 2003; 15: 401-4.

23. Sheikh I, Ahmed S, Mori N, et al. Comparison of safety and efficacy of bivalirudin versus unfractionated heparin in percutaneous peripheral intervention: a single-center experience. JACC Cardiovasc Interv 2009; 2: 871-6.

24. Shammas N, Allie D, Hall P, et al. Predictors of in-hospital and 30-day complications of peripheral vascular interventions using bivalirudin as the primary anticoagulant: results from the APPROVE registry. J Invasive Cardiol 2005; 17: 356-9. 